\title{
Field monitoring of soil-moisture to understand the hydrological response of a road-cut slope
}

\author{
Samprada Pradhan ${ }^{1 *}$, David G. Toll ${ }^{1}$, Nick J. Rosser ${ }^{1}$, and Matthew J. Brain ${ }^{1}$ \\ ${ }^{1}$ Institute of Hazard, Risk and Resilience, Durham University, UK.
}

\begin{abstract}
Rainfall and slope-cutting for road construction are two key landslide causative factors in Nepal, but how they interact to cause failures is poorly understood. To improve understanding of the effects of cut slopes during rainfall, geotechnical investigations and field monitoring were conducted in a mountainous district, Sindhupalchowk, located in central Nepal. This paper presents the results of the field-investigations and the measurements of volumetric water content obtained from the sensors installed in the study-site. Field-based evidence suggests that the slope that was cut for road construction during the dry period remained stable due to the presence of soil suction, which imparted additional strength to the soil. At the start of the monsoon, infiltration of rainwater caused saturation of the soil at shallow depth, consequently causing loss of suction and reduction of the soil strength. The presence of the road-cut in the hillslope resulting in steeper slopes then promoted the failure. These observations suggest that the presence of roadcuts in the hillslopes can cause landslides even during non-exceptional rainfall events.
\end{abstract}

\section{Background}

Landslides in Nepal are commonly associated with high amounts of rainfall during the monsoon season between June and September, which constitutes more than $80 \%$ of the total annual rainfall [1]. In addition, the construction of local roads (low-volume district and village roads) in the mountainous terrain has increased the susceptibility to landslides during rainfall [1-3]. However, how the two key factors, rainfall and roads, interact to cause landsliding is poorly understood. As the local road network is continuing to expand in Nepal as road-building is one of the main developmental priorities of the government [4], it is important to improve the understanding of the behaviour of road-related landslides during rainfall from a geotechnical perspective to prevent and mitigate such hazards in the future

This study aims to understand the role of rainfall as well as the effect of slope-cutting for road construction in causing landslides within the study area. Field investigations were conducted along a local road, where 97 slope failures occurred during 2018 monsoon. A reconnaissance field survey was carried out so as to examine the nature of the failures. A geotechnical investigation was conducted into one of the shallow slope failures along this road in order to assess the plausible causes and mechanism of the failure. With the understanding that the slope failure may have been caused by infiltration of rainwater into the unsaturated zone, Volumetric Water Content (VWC) measurement sensors and rain-gauge were installed in the field. By observing the changing relationship between rainfall and VWC, the conditions in the field that may have led to the slope failure in July 2018 were examined. In this paper, the findings from the field investigations and the measurements from the field-instruments will be presented.

\section{Study area}

The study area is a $13.7 \mathrm{~km}$ long local road from Daklang to Listi located in the Sindhupalchok district, which is approximately $105 \mathrm{~km}$ north-east from the capital city, Kathmandu (Fig. 1). This road connects the surrounding villages to the strategically important highway connecting Kathmandu to the Chinese border at Kodari. The Daklang-Listi road is located in the Upper Bhote Koshi region, which is a narrow valley with steep slopes. This area lies in the Lesser Himalayan region, which is dominated by sedimentary and metasedimentary rocks including Shale, Sandstone, Limestone, Slate, Phyllite, Schist, Dolomite, Quartzite and carbonate rocks [5-7]. The alignment of DaklangListi road runs across the hillslopes composed in some places of bare bedrock and in other places of transported soil deposits such as talus, colluvium and taluvium. 

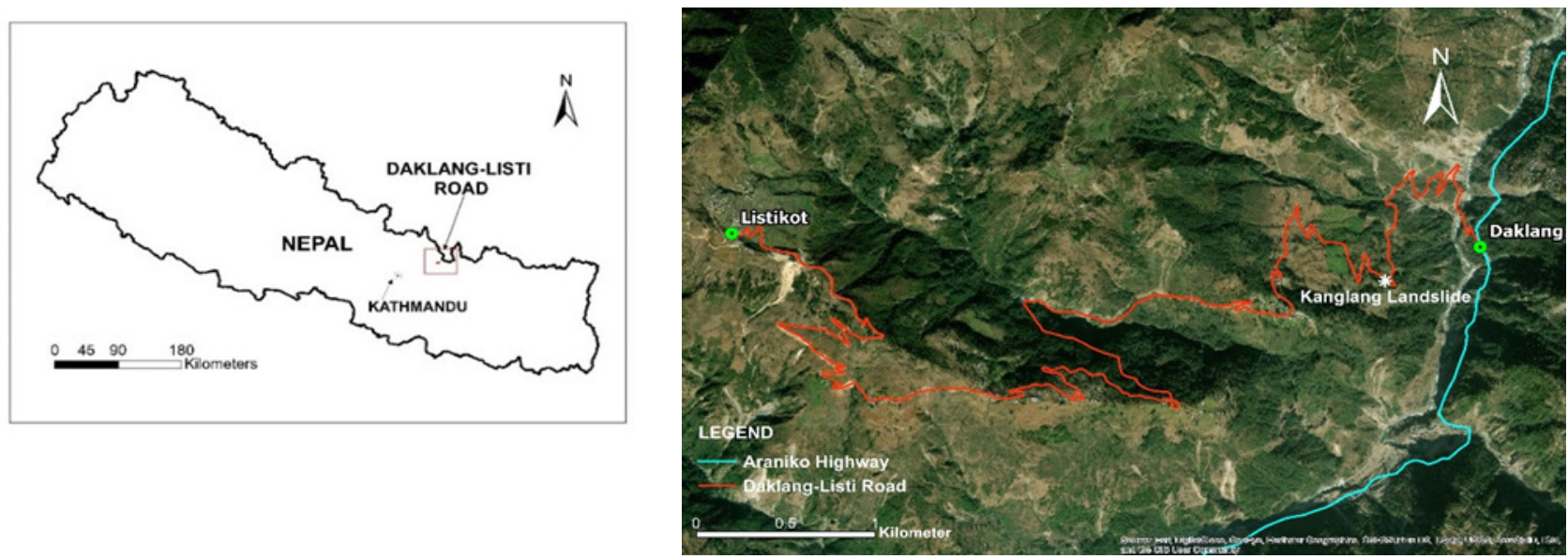

Fig. 1 Map of Nepal showing location of Daklang-Listi road (left), Daklang-Listi road alignment showing the location of Kanglang landslide (right).

\section{Reconnaissance field survey}

The reconnaissance field survey was conducted in August 2018 to characterise the types of failure along Daklang-Listi road due to monsoonal rainfall. Prior to this, two field-visits were conducted in October 2017 and December 2017, when this road was being widened by cutting the hillslopes. In December 2017 (dry period), widening of the road was nearly completed, and within 7 months of completion, 97 new landslides had occurred along this road in August 2018, disrupting the road's serviceability for almost 6 months. Based on the field observation of the failure characteristics, the landslides were classified into three major categories as shown in Fig. 2. The "failures in cut slope" were relatively small and localised in nature, while the "failures in valley slope" were mainly caused by debris-carrying surface runoff. The "failure in cut-slope extending to hillslope" was the most frequent type of failure found along the Daklang-Listi road. An example of this type of failure is the landslide located in Kanglang village, which will be referred to as Kanglang landslide hereafter (Fig. 1 and $3)$. The Kanglang landslide $\left(27^{\circ} 53^{\prime} 32.0^{\prime \prime} \mathrm{N}\right.$, $85^{\circ} 54^{\prime} 28.5^{\prime \prime E}$ ) occurred in July 2018 (Fig. 4) after the road widening was completed. The features of this landslide were obtained from direct field-measurements and have been summarised in Table 1. Based on the precipitation data from 1955 to 2018 , obtained from the nearest rainfall station at Gumthang $\left(27^{\circ} 51^{\prime} 19.1^{\prime \prime} \mathrm{N}\right.$, $\left.85^{\circ} 51^{\prime} 34.7 " \mathrm{E}\right)$, it was noted that the rainfall in July 2018 was about $40 \%$ less than the 63-year average July rainfall from 1955 to 2017 (Fig. 4). Moreover, the daily rainfall during July 2018 did not exceed $30 \mathrm{~mm}$ [8], which is significantly lower than the 24-hour rainfall threshold for landslides as identified empirically by [910] for the Himalayan slopes in Nepal. This observation suggests that Kanglang landslide was triggered by a nonexceptional rainfall event, which leads us to the understanding that other external factors like slopecutting for road construction may have contributed to the failure process.

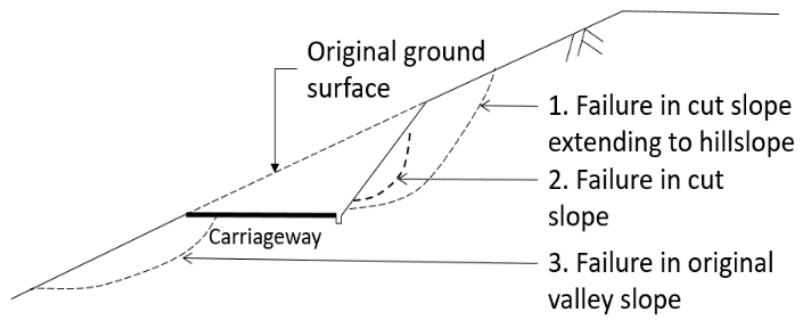

Fig. 2 Major failure types along Daklang-Listi Road (modified after [11])

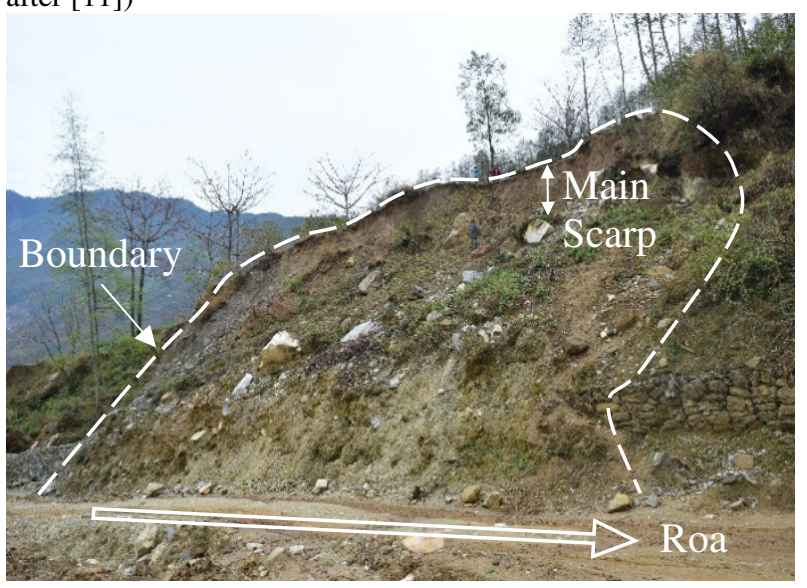

Fig. 3 Photograph of the Kanglang landslide

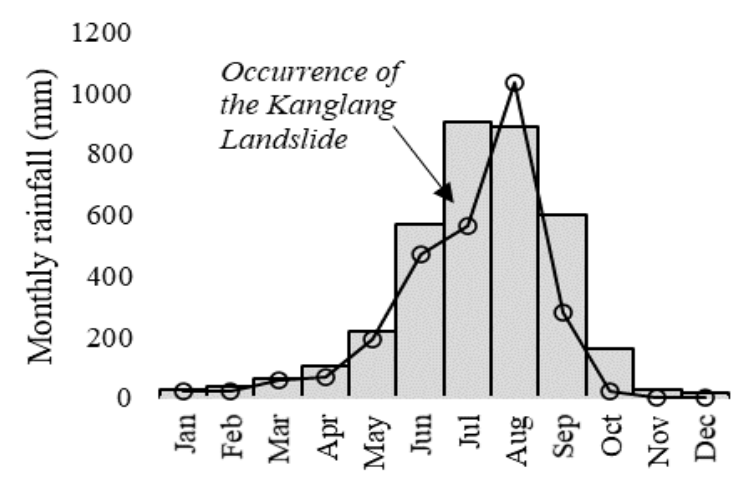

$\square$ Average Monthly Rainfall (1955 - 2017)

- Monthly rainfall in 2018

Fig. 4. Monthly rainfall in 2018 in comparison to the 63-year average measured at Gumthang rainfall station Source: [8] 
Table 1 Summary of the characteristics of Kanglang Landslide

\begin{tabular}{l|l}
\hline Length & $25 \mathrm{~m}$ \\
Width & $45 \mathrm{~m}$ \\
Depth of sliding surface & $\sim 1.5 \mathrm{~m}$ \\
Failure type & Translational slide [12] \\
Aspect & North-east \\
Elevation & $1442 \mathrm{~m}$ to $1463 \mathrm{~m}$ \\
Cut slope angle & $\sim 70^{\circ}$ \\
Hillslope angle & $\sim 23^{\circ}$ \\
\hline
\end{tabular}

\section{Geotechnical investigation}

Geotechnical investigation was carried out into the Kanglang landslide in March 2019 for the characterisation of the in-situ soils. A trial pit $(1.5 \mathrm{~m} \times 1$ $\mathrm{m})$ was excavated manually down to $1.5 \mathrm{~m}$ depth near the landslide crown $\left(27^{\circ} 53^{\prime} 28.79^{\prime \prime} \mathrm{N}, 85^{\circ} 54^{\prime} 31.69^{\prime \prime} \mathrm{E}\right)$. The ground-water table was not encountered to this depth. Disturbed and undisturbed samples were obtained from three depths: $0.3 \mathrm{~m}, 0.8 \mathrm{~m}$, and $1.2 \mathrm{~m}$. Undisturbed core samples were obtained by pushing open-ended tubes (38 $\mathrm{mm}$ internal diameter) into the pit bottom, which were then sealed with paraffin wax to limit moisture loss. The samples were imported to Durham University, UK to conduct laboratory testing. The physical parameters of the soil samples obtained from the laboratory tests are summarised in Table 2 and 3.

Atterberg limit tests were carried out as per BS EN ISO 17892-12:2018 and particle size analyses were conducted using a commercial laser diffraction particle size analyser (LS13320 analyser). The samples predominantly consisted of fine-grained soils showing border-line clay-silt behaviour and were hence, classified as silty clay of intermediate plasticity. As shown in Table 3, the in-situ water contents were lower than the plastic limits of the soils down to $1.5 \mathrm{~m}$, which indicated that the soils were in an unsaturated state [13]. Furthermore, the soils near the ground were relatively loose and porous, with lower density and higher void ratio and porosity. When compared to the soils at greater depths from the surface, the soil near the ground was less saturated (degree of saturation of $47 \%$ ), which would be expected due to atmospheric drying processes.

Table 2 Summary of physical properties of the undisturbed samples

\begin{tabular}{|l|c|c|c|c|}
\hline \multirow{2}{*}{} & \multicolumn{4}{|c|}{ Depth (m) } \\
\cline { 2 - 5 } & $\begin{array}{c}0.0 \text { to } \\
0.30\end{array}$ & $\begin{array}{c}0.30 \text { to } \\
0.50\end{array}$ & $\begin{array}{c}0.50 \text { to } \\
0.75\end{array}$ & $\begin{array}{c}0.75 \text { to } \\
1.50\end{array}$ \\
\hline Clay (\%) & 6.6 & 9.0 & 12.3 & 7.5 \\
\hline Silt (\%) & 46.2 & 56.9 & 61.8 & 56.0 \\
\hline Sand (\%) & 47.3 & 34.1 & 26.0 & 36.5 \\
\hline PL (\%) & 22.5 & 24.2 & 24.7 & 23.4 \\
\hline LL (\%) & 39.1 & 38.3 & 39.9 & 37.1 \\
\hline PI (\%) & 16.6 & 14.1 & 15.2 & 13.8 \\
\hline
\end{tabular}

PL: Plastic Limit, LL: Liquid Limit, PI: Plasticity Index
Table 3 Summary of particle size distribution and Atterberg limits for disturbed samples

\begin{tabular}{|l|c|c|c|}
\hline \multirow{2}{*}{ Properties } & \multicolumn{3}{|c|}{ Depth $(\mathrm{m})$} \\
\cline { 2 - 4 } & 0.5 & 1.0 & 1.5 \\
\hline Bulk density $\mathbf{( M g / \mathbf { m } ^ { 3 } )}$ & 1.57 & 1.85 & 1.98 \\
\hline Specific gravity & 2.72 & 2.78 & 2.75 \\
\hline Water content (\%) & 18.0 & 17.7 & 13.3 \\
\hline Void ratio & 1.04 & 0.77 & 0.57 \\
\hline Porosity (\%) & 51.0 & 43.4 & 36.4 \\
\hline Degree of saturation (\%) & 47.1 & 64.0 & 64.1 \\
\hline Dry density $\mathbf{( M g / \mathbf { m } ^ { 3 } )}$ & 1.33 & 1.57 & 1.75 \\
\hline
\end{tabular}

\section{Installation of field-monitoring station}

The two important soil parameters directly affecting the stability of the slopes during rainfall are matric suction and soil water content within the slopes. Several studies have used field monitoring of soil suction to understand the hydrological response of the slopes under infiltration conditions [14-18]. As an alternative, direct measurement of the soil moisture in terms of Volumetric Water Content (VWC) using moisture sensors is increasingly being used when suctions cannot be measured [19-21]. In this study, real-time monitoring of VWC was carried out considering the advantages of this method such as quicker response to infiltration [21] and the elimination of the need for regular maintenance. The monitoring station was installed near the crown of Kanglang landslide in March 2019. It consists of three Decagon 10HS soil moisture smart sensors (resolution: $0.0008 \mathrm{~m} 3 / \mathrm{m} 3$ ), tipping bucket-type rain-gauge (resolution: $0.2 \mathrm{~mm}$ ), and HOBO RX3000 data logger (Fig. 5). The data logger continuously records the VWC and rainfall at 1-minute interval, which can be accessed remotely.

The 10HS soil moisture sensors use a capacitancebased technique to measure the VWC. The concept is to use the sensor probes as the capacitor electrodes and the soil surrounding these electrodes as the dielectric medium to measure the total dielectric permittivity of the medium i.e. soil, which is then converted into the VWC using standard calibration equations (with $\pm 3 \%$ accuracy) [22]. In the field, the 10HS sensors were installed horizontally at $0.3 \mathrm{~m}, 0.8 \mathrm{~m}$, and $1.2 \mathrm{~m}$ depths from the ground surface on the undisturbed vertical sides of the trial pit (Section 4). In this way, a natural flow of water was assured and the possibility of preferential flow paths was avoided. A dummy metallic sensor of the same thickness and length was pushed into the pit wall prior to installing the sensors so as to prevent any damage to the sensor prongs. After installation of the sensors, the trial pit was carefully backfilled with the excavated materials in small layers, so as achieve the approximate density of the surrounding soils. The cables above the trench were placed inside a PVC pipe to prevent any damage due to the external factors. The raingauge and the data-logger were mounted on a wooden frame next to the trial pit as shown in Fig. 5. 


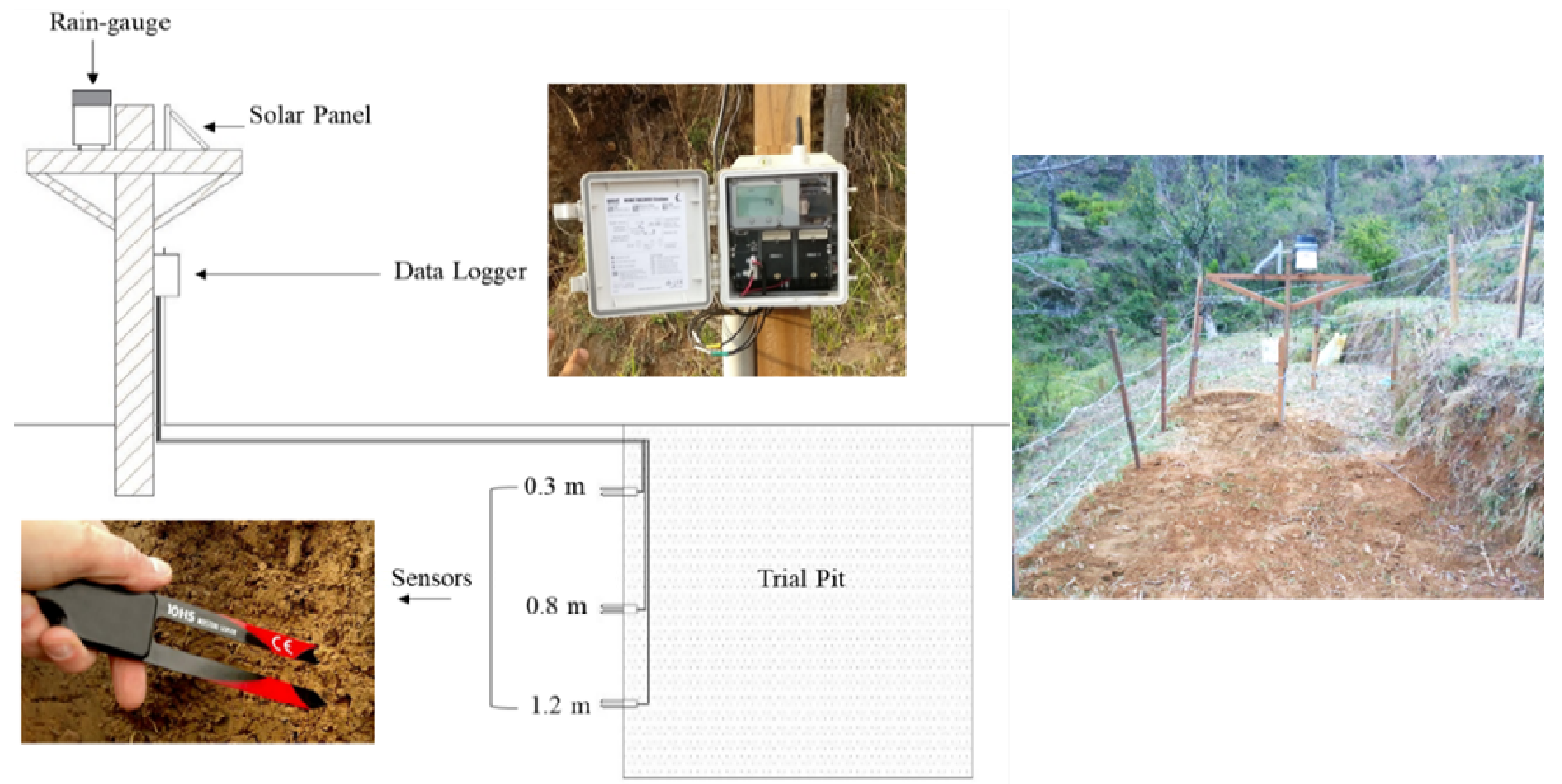

Fig. 5 (a) HOBO RX3000 data logger, (b) 10HS soil moisture smart sensor, (c) Field-monitoring set-up

\section{Field-monitoring results}

\subsection{Pre-monsoon 2019}

Fig. 6 presents the rainfall and average daily VWC measurements from 28 March to 31 August 2019. There exist notable differences in the response of the sensors located at different depths below the ground surface during this period.

The fluctuations in the VWC at $0.3 \mathrm{~m}$ was found to be directly connected to the amount of rainfall. The VWC at this layer responded quickly during and after the rainfall event, which can be attributed to the presence of surficial cracks that dominate the hydraulic conductivity of the soil near the surface. In contrast, the VWC at $1.2 \mathrm{~m}$ depth remained almost constant $(<1 \%$ change) until 31 May 2019, which indicated that the rainwater may have infiltrated beyond $0.8 \mathrm{~m}$, but did not reach to $1.2 \mathrm{~m}$.

It should be noted that the VWC at $0.3 \mathrm{~m}$ did not increase on 15 May 2019 after the rainfall event, which was comparable to the rainfall on 16 April 2019 that caused a significant increase in the VWC. This could be the effect of the prolonged dry period that existed before 15 May 2019, which caused a significant lowering of the VWC and approximately $8 \%$ decrease in the degree of saturation (Fig. 7(a)). Such a decrease may be due to evapotranspiration and vegetation roots that take up water during drying. The effect of atmospheric drying decreased with increasing depths from the surface as shown in Fig. 7(a). As a result, the soil at $1.2 \mathrm{~m}$ was wetter than the upper layers, which explains the consistently high VWC at this depth until 31 May 2019.

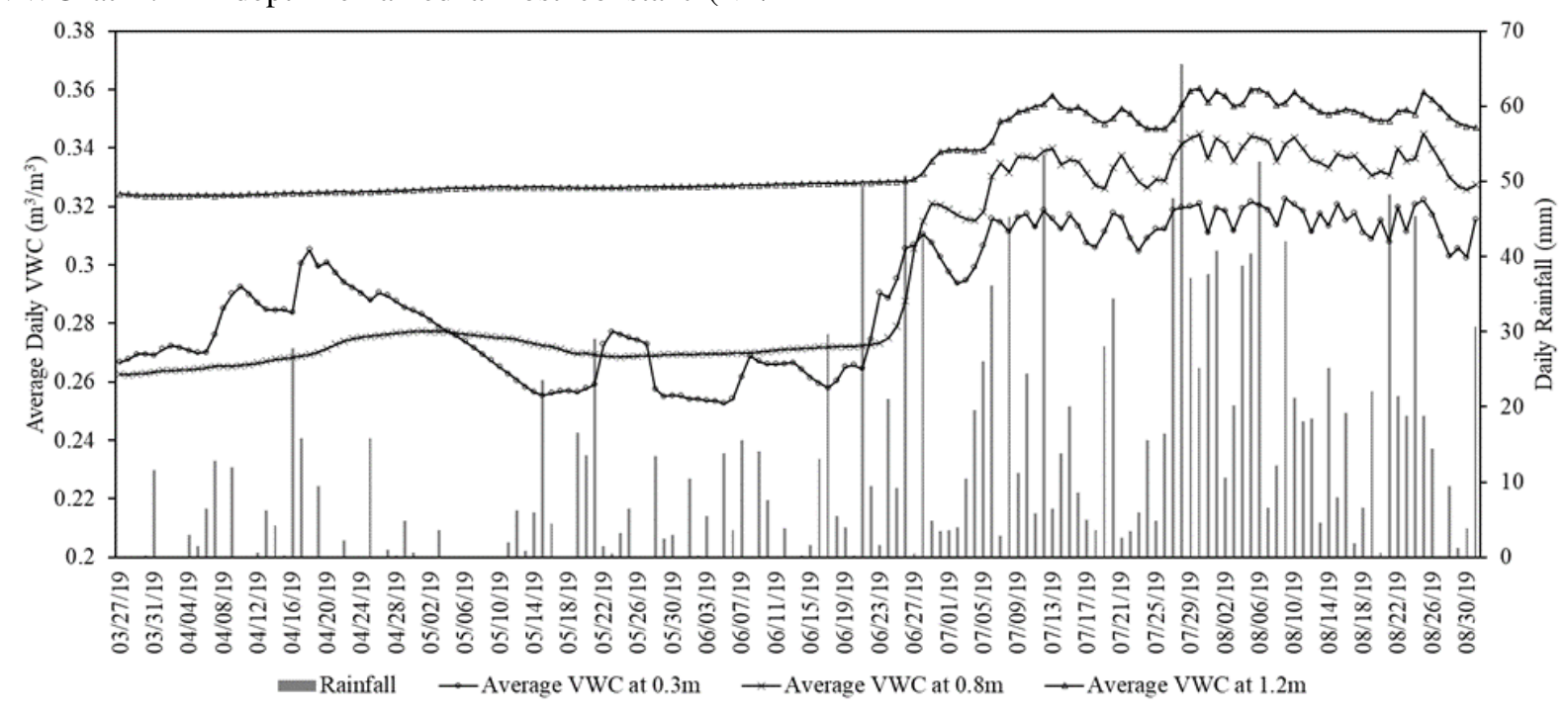

Fig. 6 Average daily VWC $\left(\mathrm{m}^{3} / \mathrm{m}^{3}\right)$ and daily rainfall (mm) between 27 March 2019 and 31 August 2019. 


\subsection{Monsoon 2019}

The variations in the daily rainfall and average daily VWC from June until the end of August 2019 are shown in Fig. 6. From the beginning of monitoring until 31 August 2019, $1840 \mathrm{~mm}$ rainfall was recorded, $85 \%$ of which occurred after 1 June 2019. Due to the heavy rainfall and consecutive wet days, changes in the VWC down to $1.2 \mathrm{~m}$ were recorded.

Similar to the pre-monsoon period, the VWC at 0.3 $\mathrm{m}$ changed quickly during and after a rainfall event. At $1.2 \mathrm{~m}$, the VWC started rising after 28 June 2019, and interestingly, not during the high-intensity, intermittent rainfall with a maximum hourly intensity of $23 \mathrm{~mm} / \mathrm{hour}$ on 26 June 2019. Moreover, the maximum hourly VWC at $0.3 \mathrm{~m}, 0.8 \mathrm{~m}$, and $1.2 \mathrm{~m}$ were recorded successively

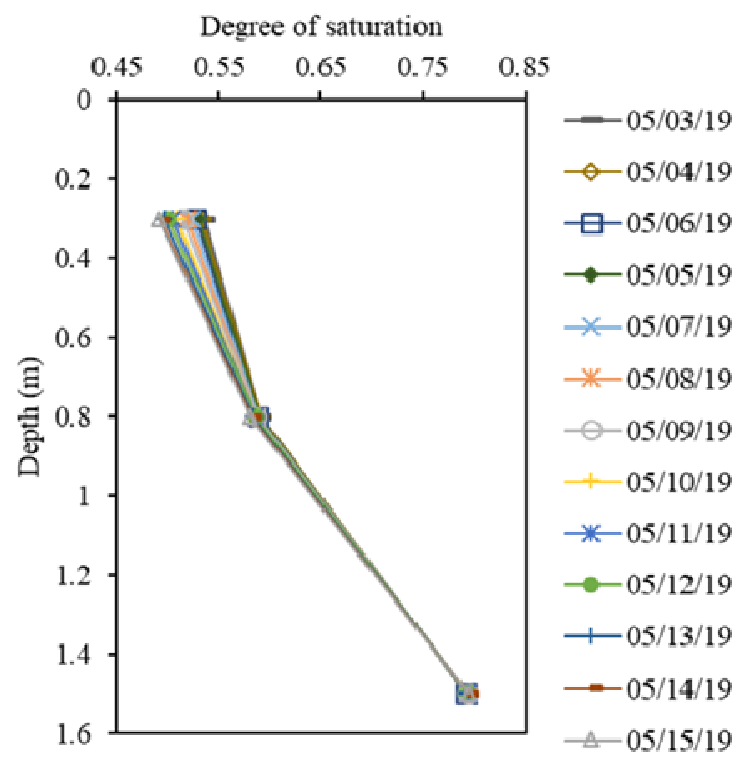

between 28 and 30 July 2019 (Fig. 8). The highest VWC at $0.3 \mathrm{~m}$ and $0.8 \mathrm{~m}$ occurred during a prolonged, heavy rainfall (64 mm in 12 hours) on 28 July 2019. Similarly, the rainfall on 30 July 2019 that increased the VWC at $1.2 \mathrm{~m}$ to maximum was a low-intensity, long-duration rainfall (42 $\mathrm{mm}$ in 10 hours). This behaviour shows that the heavy rainfall events, lasting for a relatively longer duration are capable of increasing the VWC at greater depths from the surface. During the continuous wet period between 25 and 30 July 2019, the degree of saturation increased by $\sim 3 \%$ or more at all measured depths (Fig. 7(b)). In contrast to the observations during the dry period (Fig. 7(a)), rainfall infiltration caused a notable rise in the degree of saturation down to $1.2 \mathrm{~m}$. Such progressive wetting by rainfall infiltration can cause reduction of matric suction and consequent loss of shear strength.

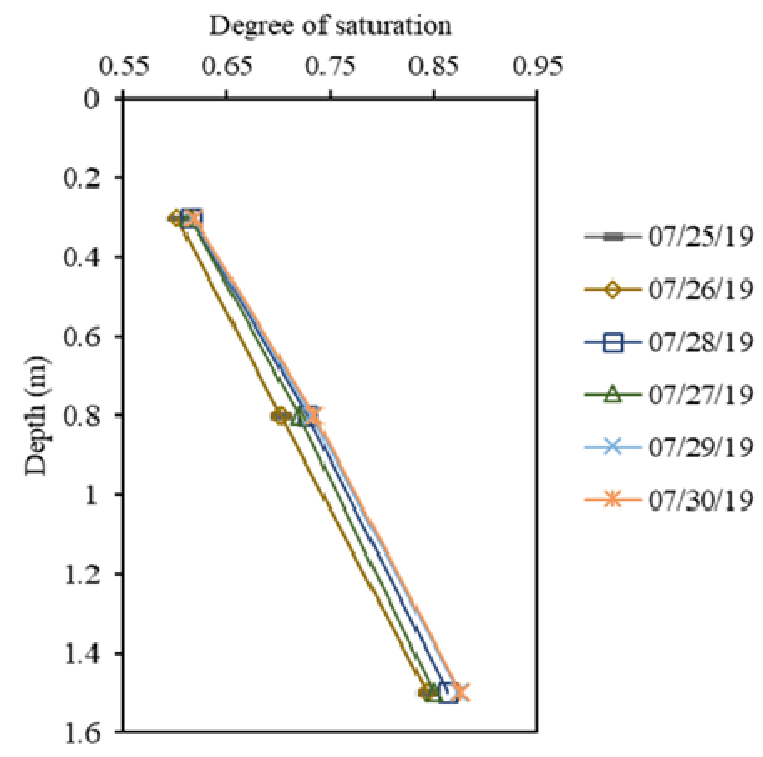

Fig. 7 (a) Variations in the degree of saturation from 3 May 2019 to 15 May 2019 (13 days), (b) Variations in the degree of saturation from 25 July 2019 to 30 July 2019 (6 days)

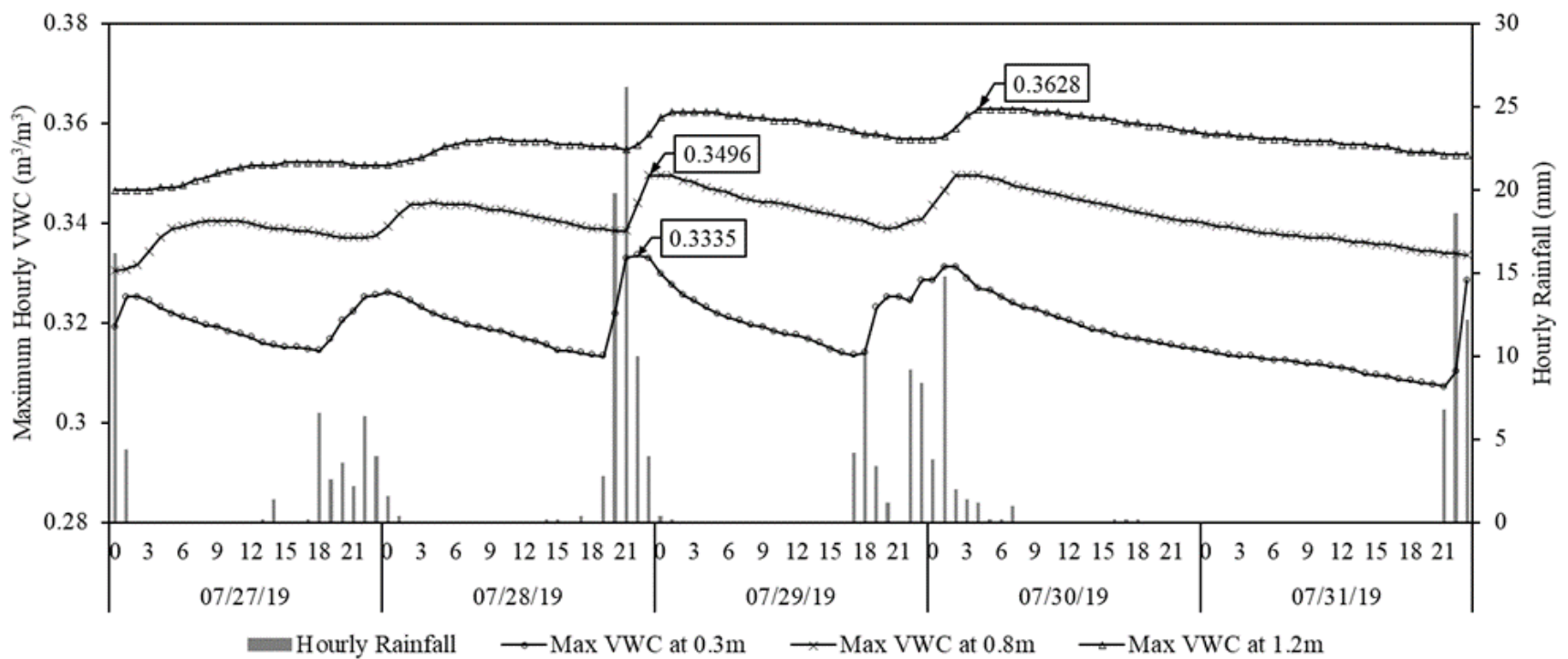

Fig. 8. Maximum hourly VWC $\left(\mathrm{m}^{3} / \mathrm{m}^{3}\right)$ and hourly rainfall $(\mathrm{mm})$ between 27 July 2019 and 31 July 2019 
Moreover, Fig. 8 highlights the pattern of the increasing response-time of VWC with depth. In general, decrease in the VWC at the upper layer is followed by increase in the VWC at the underlying layer. Such temporal variations of the VWC increments represent the infiltration pattern in the soil. If such conditions prevail throughout the depth of the soil, the decrease in the VWC at $1.2 \mathrm{~m}$ on 30 July 2019 after reaching the maximum value shall be followed by a rise in the VWC in the underlying layers. This means that the soil layer below $1.2 \mathrm{~m}$ can have a VWC greater than $0.363 \mathrm{~m} 3 / \mathrm{m} 3$. Since the porosity of the soil at $1.5 \mathrm{~m}$ is $36.40 \%$, the soil at this layer may have reached complete saturation on 30 July 2019.

In the case of Kanglang landslide in July 2018, slopecutting for road was carried out during the dry season. Due to the additional shear strength imparted by soil suction during this period, the slope may have remained stable. As observed during the 2019 monsoon (Fig. 6), rainfall infiltration in July 2018 caused increase in the VWC and hence a loss of suction can be expected in the soil layers below $1.2 \mathrm{~m}$. This loss of suction, and hence loss of shear strength, consequently could lead to failure.

\section{Conclusions}

The Kanglang Landslide occurred along Daklang-Listi road in July 2018, when the rainfall was not exceptionally high. This observation led to the understanding that steepening of the slopes due to slopecutting for road construction can promote landsliding even during non-exceptional rainfall events. Geotechnical investigation was carried out at Kanglang landslide in March 2019, which showed that the soil near the surface existed in an unsaturated state during dry periods. Monitoring of the VWC and rainfall during March-August 2019 revealed that progressive infiltration during longer-duration rainfall and consecutive wet days can cause saturation of the soils and loss of matric suction at shallow depths. Since the slope cuttings along Daklang-Listi road were carried out during the dry season (October-December), the additional shear strength imparted by matric suction in the unsaturated soils may have allowed the cut-slope at Kanglang landslide to remain stable after cutting. On the onset of 2018 monsoon, rainfall infiltration may have caused loss of suction, leading to the failure. Hence, slope-cutting for road construction, relying on the unsaturated strength of the surficial soil can be the major cause of frequent shallow landslides occurring along the hillslopes of Nepal.

This is on-going research and long-term monitoring of the VWC and rainfall is being carried out. The temporal variations of the VWC with depth reflect the drying and infiltration pattern occurring in the soils. This dataset will further be used to evaluate the influence of the slope-cuttings on the hydrological response and stability of the slopes using coupled hydro-mechanical modelling.

\section{Acknowledgements}

Special thanks to the Institute of Hazard Risk and Resilience (IHRR), Durham University, UK for funding.

\section{References}

1. D.N. Petley, G.J. Hearn, A. Hart, N.J. Rosser, S.A. Dunning, K. Oven, W.A. Mitchell, Nat. Hazards 43, 23 (2007).

2. M. Jaboyedoff, C. Michoud, M. Derron, J. Voumard, G. Leibundgut, K. Sudmeier-Rieux, C. Michoud, F. Nadim, E. Leroi, Landslides and Engineered Slopes. Experience, Theory and Practice (CRC Press, 2018).

3. G.J. Hearn, N.M. Shakya, Q. J. Eng. Geol. Hydrogeol. 2017 (2017).

4. R. Pokharel, S.R. Acharya, T. Investment, J. East. Asia Soc. Transp. Stud. 11, 209 (2015).

5. J. Stöcklin, J. Geol. Soc. London. 137, 1 (1980).

6. R. Dahal, Geology for Technical Students (2006).

7. B.N. Upreti, Landslide Hazard Mitig. Hindu KushHimalayas 31 (2001).

8. DHM Department of Hydrology and Meteorology (DHM), (2018).

9. N. Caine, P.K. Mool, Mt. Res. Dev. 2, 157 (1982).

10. R.K. Dahal, S. Hasegawa, A. Nonomura, M. Yamanaka, S. Dhakal, P. Paudyal, Geomorphology 102, 496 (2008).

11. G.J. Hearn, Slope Engineering for Mountain Roads (Geological Society of London, London, 2011).

12. D.J. Varnes, in Landslides Eng. Pract., edited by E.B. Eckel (National Research Council, Washington, D.C., 1958).

13. H. Rahardjo, E.C. Leong, R.B. Rezaur, in Proc. Natl. Semin. Slope 2002 (Bandung, 2002), pp. 15-29.

14. D.G. Toll, S.D.N. Lourenço, J. Mendes, D. Gallipoli, F.D. Evans, C.E. Augarde, Y.J. Cui, A.M. Tang, J.C. Rojas, L. Pagano, C. Mancuso, C. Zingariello, A. Tarantino, Q. J. Eng. Geol. Hydrogeol. 44, 23 (2011).

15. O. Augusto Filho, M.A. Fernandes, Bull. Eng. Geol. Environ. (2018).

16. H. Rahardjo, V.A. Santoso, E.C. Leong, Y.S. Ng, C.J. Hua, Soils Found. 51, 471 (2011).

17. S. Jeong, K. Lee, J. Kim, Y. Kim, Sustainability 9 , 1280 (2017).

18. I. Tsaparas, H. Rahardjo, D.G. Toll, E.C. Leong, Can. Geotech. J. 40, 1012 (2003).

19. Y.K. Kim, D. Ph, S.R. Lee, M. Asce, J. Geotech. Geoenvironmental Eng. 136, 248 (2010).

20. S.J. Harris, R.P. Orense, K. Itoh, Landslides 9, 349 (2012).

21. B.-G. Chae, M.-I. Kim, Environ. Earth Sci. 66, 1973 (2012).

22. G. Kargas, K.X. Soulis, J. Irrig. Drain. Eng. 138, 632 (2012). 